\title{
De la potestad marital a la violencia económica y patrimonial en Colombia
}

\author{
From Marital Power to Economic and \\ Patrimonial Violence in Colombia \\ Do poder matrimonial à violência econômica \\ e patrimonial na Colômbia
}

\author{
Carmen Diana Deere* \\ MAGDALENA LEÓN ${ }^{* *}$
}

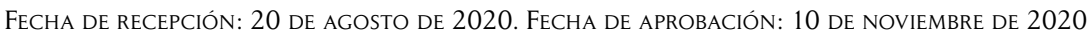

Doi: https://doi.org/10.12804/revistas.urosario.edu.co/sociojuridicos/a.9900

Para citar este artículo: Deere, C. D., E León, M. (2021). De la potestad marital a la violencia económica y patrimonial en Colombia. Revista de Estudios Socio-Jurídicos, 23(1), 219-251. https://doi.org/10.12804/revistas.urosario. edu.co/sociojuridicos/a.9900

\section{RESUMEN}

La herencia colonial hispana sobre la desigualdad de género en el matrimonio quedó resumida en el primer código civil colombiano dentro del concepto de potestad marital, en términos de los derechos del marido sobre la persona y bienes de la mujer. Tomó casi un siglo desmontarlo legalmente, lo cual se logró al reconocer dicho control como violencia económica y patrimonial. Desde 2008 se reconoce este tipo de violencia como una forma de violencia contra la mujer; sin embargo, los datos indican una alta incidencia de violencia económica y patrimonial por parte de la pareja o expareja, especialmente entre mujeres separadas y divorciadas, y entre las que están en uniones de hecho comparadas con las casadas. Se evidencia la prevalencia cultural de la lógica patriarcal y también se explica por qué esta forma de violencia ha recibido poca atención institucional.

Palabras clave: derechos de propiedad de la mujer; violencia de pareja; reformas legales.

* Profesora Distinguida Emérita de estudios latinoamericanos y economía agrícola, Universidad de Florida, y Profesora Distinguida, Flacso-Ecuador. Correo electrónico: deere@ latam.ufl.edu

** Profesora Titular de sociología, Escuela de Estudios de Género, Facultad de Ciencias Humanas, y Doctorado Honoris Causa, Universidad Nacional de Colombia. Correo electrónico: magleon09@gmail.com 


\section{ABSTRACT}

In Colombia's first legal code, the Spanish colonial legacy of gender inequality in marriage was summed up in the concept of marital power -the husband's legal authority over his wife and her property. It took nearly a century to legally dismantle it, to the point that a husband's control over the income and assets of his wife now constitutes economic and patrimonial violence. While economic and patrimonial violence has been recognized as a form of violence against women since 2008, survey data indicate a high incidence of this form of intimate partner violence particularly, among separated and divorced women, and those in consensual unions as compared to married women. This shows how difficult patriarchal control is to change culturally, and why this form of violence has received little institutional attention.

Keywords: women's property rights; intimate partner violence; legal reform.

\section{RESUMO}

A herança colonial hispânica sobre a desigualdade de gênero no casamento foi resumida no primeiro código civil colombiano dentro do conceito de poder conjugal, em termos dos direitos do marido sobre a pessoa e os bens da mulher. Demorou quase um século para desmontá-lo legalmente, o que foi conseguido reconhecendo esse controle como violência econômica e patrimonial. Desde 2008, esse tipo de violência é reconhecido como uma forma de violência contra a mulher; no entanto, os dados indicam uma alta incidência de violência econômica e patrimonial por parte do companheiro ou ex-companheiro, especialmente entre mulheres separadas e divorciadas, e entre aquelas em união estável. Evidencia-se a prevalência cultural da lógica patriarcal e, também se explica por que essa forma de violência tem recebido pouca atenção institucional.

Palavras-chave: direitos de propriedade das mulheres; violência por parceiro intimo; reformas legais. 


\section{Introducción}

Colombia incorporó en su Código Civil de 1873 la definición de la potestad marital del código civil de Andrés Bello, como "el conjunto de derechos que las leyes conceden al marido sobre la persona y bienes de la mujer" (Colombia 1895, artículo 177). Esta frase resume la herencia colonial hispana sobre la desigualdad de género en el matrimonio. Tomó casi un siglo desmontar legalmente la potestad marital, al reconocer como violencia económica y patrimonial (E/P) el control del marido sobre la persona y los bienes de la mujer.

Durante el siglo XX se expandieron los derechos de propiedad de la mujer casada, en paralelo con la primera ola del movimiento feminista $\mathrm{y}$, desde los setenta, gracias al impulso de la segunda. El mayor logro se consiguió en 2008, con el reconocimiento de la violencia E/P como una forma de violencia contra la mujer. Hoy en día, debido a la alta incidencia de violencia $\mathrm{E} / \mathrm{P}$ y a la interrelación entre las diferentes formas de violencia, el reto es hacer cumplir los derechos de propiedad de la mujer y su derecho a una vida libre de violencia.

La violencia económica y la violencia patrimonial suelen tratarse como si fueran lo mismo. Pero, aunque están interrelacionadas, conceptualmente son diferentes. Definimos la violencia patrimonial como la violación a los derechos de propiedad de la mujer; es decir, a su derecho a administrar su propiedad individual y a disfrutar de los bienes comunes adquiridos durante el matrimonio -esto es a recibir la mitad de ellos al disolverse la sociedad conyugal-y a sus derechos de sucesión. La violencia económica se refiere a las acciones que limitan la capacidad de la mujer para generar o administrar ingresos, tanto los suyos como los de su pareja en beneficio del hogar.

Poco se ha estudiado la violencia E/P. ${ }^{1}$ Es una manifestación de las relaciones de poder, específicamente de dominación y control sobre la mujer, y se relaciona con la dependencia económica. En el siglo XIX $y$ hasta finales del $\mathrm{xx}$, el ideal de familia era el modelo del hombre proveedor y la mujer ama de casa. Esta visión tradicional sustentaba su

Estudios pioneros sobre el tema incluyen Deere et al. (2014), Hasanbegovic (2018), y para Colombia, Friedemann-Sánchez (2012) y Alviar García (2018). 
armonía en la lógica de la famosa frase Napoleónica, "el marido debe protección a la mujer y la mujer obediencia al marido". En este modelo el conflicto era latente. Por el lado del hombre, si no podía (o no quería) cumplir con su deber de sostén económico del hogar, y por el lado de la mujer, si no aceptaba la maternidad, el trabajo doméstico y de cuidado. Igualmente, si se violaba la premisa implícita de protección/ obediencia por infidelidad. Como los derechos de propiedad de la mujer eran relativamente débiles y el matrimonio no se podía disolver, la mujer casada era una dependiente casi total y tenía poco poder de negociación en el matrimonio.

Durante el siglo XX, esta situación empezó a cambiar con la entrada de la mujer al mercado laboral y con la expansión de sus derechos para adquirir y administrar ingresos y activos, factores asociados al incremento de su poder de negociación en la relación. La aprobación del divorcio civil fue también fundamental en este sentido. Sin embargo, nuestro análisis demuestra que los cambios legales son condición necesaria pero no suficiente para romper con la potestad marital en la práctica.

La violencia E/P se da tanto en lo privado como en lo público. En este trabajo se privilegia el análisis en el hogar y la relación de pareja sin desconocer las desigualdades de género en el mercado laboral. Estas limitan el poder de negociación que le da a la mujer un empleo o adquirir sus propios activos, elementos que contribuyen a reproducir su dependencia económica en el matrimonio.

Entre nuestros hallazgos empíricos más destacados, provenientes del análisis de la Encuesta Nacional de Demografía y Salud de 2015, está que la violencia E/P varía según el estado civil. Las tasas más altas se presentan en las mujeres divorciadas o separadas. La violencia en sus diferentes formas es muchas veces la causal de la ruptura; no obstante, la patrimonial en particular, se presenta especialmente en los momentos de separación, cuando se dividen los activos acumulados durante la relación. Llama la atención que las mujeres en unión libre reportan la incidencia más alta de todas las formas de violencia en comparación con las casadas. Sobre la violencia E/P, los datos muestran que los derechos de propiedad reconocidos para estas uniones en 1990 no han tenido suficiente divulgación. 
La primera parte del trabajo presenta los elementos constitutivos de la potestad marital y señala los que son herencia legal colonial y las innovaciones de Bello. Se sigue con las reformas a los derechos de propiedad en Colombia para las mujeres casadas en el siglo XX. Luego, se presenta la evolución de la legislación de violencia intrafamiliar que incorporó la violencia E/P. A continuación, se analizan los datos disponibles sobre la incidencia de la violencia $\mathrm{E} / \mathrm{P}$ y las deficiencias en la medición de este indicador. Finalmente, se examina la ruta crítica de concientización y acción de las mujeres que han sufrido violencia, la cual ha recibido poca atención desde la óptica de la violencia E/P.

\section{Los derechos de propiedad de las mujeres}

Durante el gobierno de la Federación, varios de los Estados soberanos habían adoptado sus propios códigos civiles, y el código civil de 1858 del Estado de Santander sirvió de modelo para el primer código civil nacional, expedido en 1873. A su vez, el de Santander se había adoptado, con pequeñas modificaciones, del Código Civil de Chile de 1855 de autoría de Andrés Bello (Valencia Zea, 1987). El código civil de Bello tuvo gran influencia en América Latina por combinar elementos de la tradición legal Hispana colonial, en lo social, con corrientes europeas como el código Napoleónico, en lo económico (Mirow, 2001).

El Código Civil Colombiano de 1887 (Ley 57 de 1887) ratificó el código de 1873, con algunas modificaciones. A continuación se señalan aspectos relevantes a los derechos de propiedad de las mujeres en los cuales el código colombiano reprodujo o se distanció del código de Bello. ${ }^{2}$ También se señalan temas en que el código de Bello siguió o se apartó de la tradición legal colonial Hispana. ${ }^{3}$

2 Las referencias a artículos son de la edición oficial del Código Civil de 1887 impreso en 1895; las citas en texto aparecen como Colombia (1895). Se compara estos artículos con el código de 1873 gracias a la versión disponible en internet, en www.icbg.gov.co, la cual contiene notas sobre la legislación anterior. Si no se explicita, no hay diferencias entre el código de 1873 y 1887 .

3 Análisis basado en Deere y León (2005). 
En la tradición colonial Hispana, igual que en el código de Bello, la mujer tenía capacidad jurídica, aunque sus derechos de propiedad eran diferentes según su estado civil. Las mujeres solteras y viudas tenían casi los mismos derechos que sus pares masculinos. El matrimonio introdujo las desigualdades de género en los derechos de propiedad. La capacidad jurídica se establecía por la mayoría de edad, que permitía heredar y administrar propiedades y sus propios ingresos $\mathrm{y}$, en algunos casos, casarse sin el permiso de los padres.

En Colombia, el Código de 1873 estableció la mayoría de edad a los 21 años para mujeres y hombres (Colombia 1895, artículo 34). Mantuvo una diferencia de género en la edad para contraer matrimonio sin permiso de los padres, de 18 para mujeres y 21 para hombres. ${ }^{4}$ En ambos temas, Colombia se distanció del Código de Bello. Este mantuvo la norma colonial y la mayoría de edad y la de contraer matrimonio fue de 25 años para ambos sexos (Deere \& León 2005, cuadro 3).

Como ya mencionamos, Colombia siguió al pie de letra la definición de Bello de la potestad marital, la cual contiene los elementos - heredados de la tradición colonial- que disminuyen la capacidad jurídica de la mujer casada, haciéndola relativamente incapaz, poniendo al marido como el jefe de familia. Entre ellos están los siguientes:

- El marido debe protección a la mujer y la mujer obediencia al marido (artículo 176).

- La mujer está obligada a vivir donde el marido determina y seguirle (artículo 178).

- Con el matrimonio se establece la sociedad de bienes y el marido es el administrador de estos y de los bienes de la mujer (artículos 180 y 1805).

- Sin permiso del marido, la mujer no puede entrar en juicio (artículo 181).

- Sin permiso del marido, la mujer no puede celebrar contratos de ningún tipo (artículo 182). 
Los roles de género en el matrimonio - el marido debe protección y la mujer, obediencia - fueron una de las pocas frases sobre la familia que Bello tomó directamente del Código Napoleónico, y se las considera la pieza central de la jefatura masculina (Deere E León, 2005). Al parecer, esta frase no estaba en el código de 1873 sobre obligaciones mutuas: "Los cónyuges están obligados a guardarse fe, a socorrerse y ayudarse mutuamente en todas las circunstancias de la vida". La desigualdad de género que implica el deber de protección a cambio de la obediencia fue introducida por la reforma conservadora en las obligaciones mutuas en el artículo 176 del Código de 1887.5

La protección que el hombre, como jefe de hogar, le debe a la mujer está en el artículo 178 sobre la residencia, que aunque definida por el hombre, la mujer tenía derecho a que el marido la recibiera en su casa. Además, el artículo 179 estableció que "el marido debe suministrar a la mujer lo necesario según sus facultades". Aquí Bello introdujo una innovación (en comparación con la tradición colonial o el código francés) cuando añadió: "la mujer tendrá igual obligación respecto del marido, si este careciere de bienes".

El matrimonio, si antes no se hacen capitulaciones, establecía automáticamente la sociedad de bienes, conocida como la sociedad conyugal (artículo 1774). Según el modelo de Bello, la sociedad conyugal está compuesta por la propiedad común (lo adquirido con cualquier ingreso durante el matrimonio) y lo que la sociedad está obligada a restituir a cada uno de los cónyuges al disolverse. Como parte de la propiedad individual por restituir está el dinero y bienes muebles aportados por cualquiera de los cónyuges y los bienes inmuebles aportados por la mujer. Las donaciones, herencias o legados recibidos también son parte de la propiedad individual de cada uno (artículo 1782).

El código de Bello y el colombiano mantuvieron la flexibilidad que en la práctica ofrecían las capitulaciones previas al matrimonio en el periodo colonial. La pareja podría determinar cuáles bienes aportaba a la

5 Refiriéndose al código de 1873, Jaramillo (2013) destaca que "El Código de Bello sufrió muchas modificaciones para hacerlo compatible con el clima político más liberal predominante en Colombia. En 1887, sin embargo, muchas de esas modificaciones se cambiaron de nuevo a la versión original" (p. 179). No analiza las normas sobre las obligaciones y derechos entre los cónyuges, que son nuestro interés. 
sociedad conyugal, incluidas donaciones entre ellos (artículos 1771-1775). También se estipuló de manera explícita que la mujer podía administrar "una parte de sus bienes propios con independencia del marido" y, de igual manera, una suma de dinero o pensión periódica (artículo 1776).

El código de Bello fue también relativamente flexible sobre la requerida autorización del marido para las transacciones económicas de la mujer, la cual podía ser general o especial (Colombia 1895, artículo 185). Por ejemplo, podía ratificar un contrato que la mujer había hecho sin su permiso (artículo 187). Se asumía igualmente que la mujer tenía permiso general para comprar bienes muebles al contado o al fiado si eran para el consumo ordinario (artículo 192). De especial importancia fue la excepción a las mujeres que ejercen "alguna profesión, industria u oficio". En este caso también se presumía "la autorización general del marido para todos los actos y contratos concernientes (...) mientras no intervenga reclamación o protesta de su marido" (artículo 195).

Entre las innovaciones de Bello a los derechos de propiedad de la mujer, que adopta el código colombiano, está la eliminación del trato especial a la dote. Por otro lado, dio protección especial a los bienes inmuebles de la mujer y amplió las condiciones para la separación de bienes. Los bienes inmuebles de la mujer, solo en casos especiales, podrían ser enajenados o hipotecados por el marido, la mujer o ambos (artículo 189). Se requería tanto el consentimiento de la mujer como el decreto de un juez o prefecto y solamente en los casos previstos en las capitulaciones matrimoniales o "de necesidad o utilidad manifiesta de la mujer" (artículo 1810). Con el simple consentimiento de la mujer, el marido podía enajenar los bienes muebles que estaba obligado a restituir en especie (artículo 1811).

En el periodo colonial, la simple separación de bienes se daba en dos casos: por un divorcio eclesiástico y por petición de la mujer por mala administración de su dote. Con la extinción de la dote, el código de Bello extendió este derecho a la mujer en caso de "insolvencia o administración fraudulenta del marido" (artículo 200). A través del juicio de separación de bienes la mujer podría recuperar y administrar sus bienes propios, y Bello mejoró su posición porque ella también podría administrar su mitad de los bienes gananciales de la sociedad conyugal. No requería la autorización del marido para administrar estos 
bienes ni para realizar contratos, aunque sí para ser parte de un juicio (artículo 204).

En cuanto a la herencia, el código de Bello y el colombiano mantuvieron dos aspectos importantes de la tradición colonial sobre la posición de la mujer. Primero, la mujer casada tenía el derecho de hacer un testamento para disponer de su propio patrimonio sin la autorización del marido (artículo 185) y, segundo, en la sucesión intestada "no se atiende al sexo ni a la primogenitura" (artículo 1039); es decir, todos los hijos legítimos heredan por igual. ${ }^{6}$

El código de Bello mejoró la posición del cónyuge en la sucesión intestada, que en la tradición colonial no formaba parte de los herederos. El cónyuge pasó al segundo orden de sucesión junto con los padres del difunto y los hijos naturales (artículo 1046). Además, se formalizó la práctica colonial de la cuota viudal en la llamada porción conyugal, definida por Bello como "aquella parte del patrimonio de una persona difunta que la ley asigna al cónyuge sobreviviente que carece de lo necesario para su congrua subsistencia" (artículo 1230), la cual no podría sobrepasar un cuarto del patrimonio (artículo 1236).

En resumen, en el siglo XIX se dieron importantes cambios sobre la herencia, con énfasis en la familia conyugal. No obstante, los códigos de Bello y de Colombia no dieron pasos grandes en esta dirección como Bolivia, Argentina y Venezuela, que elevaron al cónyuge al primer orden de la sucesión intestada (Deere E León, 2005).

\section{Las reformas del siglo $X X$}

En el momento en que Colombia aprobó su código civil de 1887, otros países de América Latina cuestionaban la conveniencia de la potestad marital. Durante las revoluciones Liberales centroamericanas -entre 1887 y 1906- Costa Rica, El Salvador, Nicaragua y Honduras dieron a las mujeres casadas los mismos derechos de propiedad que tenían las solteras, al adoptar el régimen matrimonial de separación de bienes. En este régimen, cada cónyugue es dueño y administrador de los

6 No entramos en la situación de los hijos ilegítimos y otros aspectos de la patria potestad; ver Jaramillo (2013) y Gómez Chíquiza (2019). 
bienes adquiridos antes del matrimonio, de los heredados o donados, $\mathrm{y}$ de los adquiridos con sus salarios $\mathrm{u}$ otros ingresos durante el matrimonio. Para la administración y disposición de sus bienes, las mujeres casadas ya no necesitarían autorización del marido o de un juez y libremente podrían firmar contratos y entrar en juicios (Deere E León, 2005).

Ecuador fue el primer país de Suramérica en ampliar los derechos de propiedad de las mujeres casadas en 1911, seguido por Brasil y Venezuela en 1916, Chile en 1925 y Argentina en 1926 (Deere, 2020). En Colombia, solo a comienzos de la década del veinte se inició la discusión de los derechos de propiedad de las mujeres casadas, liderada por los partidos socialista y liberal (Velásquez Toro, 1989).

La Ley 8 de febrero de 1922 reformó el código civil, confirmando lo ya establecido en el código de 1887 sobre los bienes señalados en las capitulaciones matrimoniales, dándole a la mujer casada el derecho de administración y uso libre de estos bienes. Además, aclaró un derecho que la mujer casada tenía en el periodo colonial sobre la administración de los llamados bienes parafernales (sus vestidos, ajuares y joyas), lo novedoso fue que añadió "instrumentos de su profesión u oficio". A la vez, señaló "que de estos bienes no podrá disponer en ningún caso por si solo uno de los cónyuges" (artículo 1), por lo cual entendemos que no era posible enajenarlos.

Esta ley amplió las causales bajo las cuales se podría demandar la separación de bienes de la sociedad conyugal, para incluir los "que autorizan el divorcio por hechos imputables al marido" y la disipación y el juego habitual (artículo 2). Mejoró la situación económica de la mujer divorciada por cometer adulterio al no perder sus gananciales. Finalmente, expandió los derechos civiles de todas las mujeres, permitiéndoles ser testigos bajo los mismos requisitos y excepciones que los hombres (artículo 4).

Paulatinamente se fueron ampliando los derechos de propiedad de las mujeres casadas. La Ley 124 de 1928 estableció que ellas podían tener sus propias cuentas de ahorro, las que se consideraban "bienes propios" (artículo 12). La Ley 83 de 1931 estipuló que la mujer casada que trabajara podía recibir su salario directamente y administrarlo (artículo 24). Y la Ley 67 de 1930 estableció que la mujer divorciada recobraba su plena capacidad legal (Gómez Chíquiza, 2019). 
Con la realización del Cuarto Congreso Internacional Femenino, en diciembre de 1930 en Bogotá, auspiciado por la Liga Internacional de Mujeres Ibéricas e Hispanas, se puede hablar del surgimiento de un movimiento feminista en Colombia (Luna 1985; Velásquez Toro 1989; Beltrán \& Puga, 2019). Este congreso fue uno entre los varios organizados por las diferentes redes feministas interamericanas durante la primera mitad del siglo XX. Este coincidió con el regreso del partido Liberal al poder y la presidencia de Enrique Olaya Herrera, con su agenda modernizadora y compromiso por los derechos económicos de las mujeres casadas. Entre 1930 y 1932 se presentaron cuatro proyectos de reforma al régimen matrimonial que no prosperaron, hasta que finalmente el quinto fue aprobado (Gómez Molina, 2015). Las mujeres jugaron un importante rol de lobby para lograr este resultado.

La Ley 28 de 1932 fue transcendental en cuanto abolió la mayoría de los elementos vigentes de la potestad marital. Dio a cada cónyugue la libre administración y disposición de los bienes que le pertenecían antes de casarse y de los adquiridos durante el matrimonio (artículo 1). También mantuvo la sociedad conyugal como el régimen legal si la pareja no estipulaba otros arreglos en las capitulaciones matrimoniales. En el momento de su disolución, se asumía que esta había sido constituida desde la celebración del matrimonio. Es decir, al momento de liquidarse la sociedad conyugal, se aplicaban las mismas reglas del código civil en cuanto a la división en partes iguales de los gananciales netos. Por otro lado, esta reforma dio a la mujer casada los mismos derechos civiles que tenían las mujeres solteras. El marido dejó de ser el representante legal de su mujer (artículo 5).

A nuestro juicio, esta fue la reforma más completa en Suramérica hasta ese momento (Deere, 2020). Valencia Zea y Ortíz Monsalve (1995) consideran que fue inspirada por la reforma realizada en Costa Rica en 1887 y algunas europeas, como la de Hungría. A diferencia de Colombia, la reforma de Costa Rica estableció un régimen de separación de bienes como el que regía durante el matrimonio si no se establecía otro en las capitulaciones; a la vez, requirió que, al disolverse, se contaran los gananciales de cada uno y se dividieran en partes iguales entre los cónyuges. En la literatura internacional, esta variante se conoce como el régimen de comunidad diferida (Glendon, 1989). En contraste, el de 
Colombia se conoce actualmente como el régimen de participación de gananciales o sociedad de gananciales (Amézquita, 1977; Valencia Zea E Ortiz Monsalve, 1995).

La primera ola del movimiento feminista llegó a su auge durante la década de 1940, pero no logró su otra meta: el sufragio femenino, que se obtuvo en 1954 (Luna ,1985; Velásquez Toro, 1989). Las reformas que abolieron todo vestigio de la potestad marital tuvieron que esperar un par de décadas más a la segunda ola del movimiento feminista, en la década de los 1970, y a condiciones políticas favorables, como la presidencia de López Michelsen, quien en su campaña electoral prometió eliminar los rezagos discriminatorios contra la mujer en el código civil (Beltrán \& Puga, 2019).

El Decreto 2820 de 1974, conocido como Estatuto de Igualdad Jurídica de los Sexos, estableció la doble jefatura del hogar, otorgó a los cónyuges las mismas obligaciones y responsabilidades en la dirección y administración del hogar, y consagró la obligación mutua de vivir juntos y fijar residencia. También derogó la incómoda frase napoleónica del artículo 176. Esta legislación igualó los restantes derechos civiles de mujeres y hombres; por ejemplo, que la mujer casada podía ser fiadora y albacea testamentaria y ejercer la patria potestad sobre los hijos menores junto con el marido. En este mismo periodo se expandieron las causas para la separación de bienes (1975), al incluir el mutuo consenso, ${ }^{7}$ y se logró el divorcio vincular (1976) para los casados por lo civil, con el derecho de volverse a casar. ${ }^{8}$ No fue sino hasta 1992 que se admitió el divorcio civil para el matrimonio religioso y por mutuo consenso. ${ }^{9}$

Otra reforma de los derechos de propiedad de las mujeres de suma importancia fue el reconocimiento de las uniones de hecho por la Ley 54 de $1990 .{ }^{10}$ Estas siempre han sido comunes en Colombia, pero desde

7 Decreto 772 de 30 abril de 1975. Valencia Zea y Ortiz Monsalve (1995) consideran que desde entonces las capitulaciones matrimoniales se pueden hacer antes o después del matrimonio.

8 Ley 1 de 1976. Beltrán y Puga (2019) analiza los factores que posibilitaron esta legislación.

9 Ley 25 de 1992.

10 Sobre las modificaciones hechas en los años noventa a la protección al patrimonio de familia, ver Gómez Chíquiza (2019). 
la década de 1970 crecieron rápidamente (Esteve et al., 2016). El Censo de 2018 revela que de las mujeres en edad reproductiva (15 a 49 años) que viven con una pareja, el $66.3 \%$ están en unión de hecho y no en matrimonio. ${ }^{11}$ Anteriormente, las parejas convivientes implícitamente tenían un régimen de separación de bienes porque al disolverse la unión por separación o muerte, no había un patrimonio común legalmente reconocido para que la mujer pudiera reclamar su mitad.

La Ley 54 de 1990 definió una unión marital de hecho (UMH) como la "formada por un hombre y una mujer que, sin estar casados, hacen una comunidad de vida permanente y singular" (artículo 1); los denominó compañero y compañera permanente. Estableció que después de dos años de convivencia, si no había impedimentos para casarse, se presumía una "sociedad patrimonial", siguiendo las reglas de la sociedad conyugal. Si había impedimentos (en que uno de ellos estaba casado/a con otro/a), igualmente se podía formar una sociedad patrimonial si la sociedad conyugal de esa persona se había disuelto y liquidado por lo menos un año antes al inicio de la UMH. ${ }^{12}$ En 2005, por la Ley 979, se amplió la forma para establecer una UMH por trámite en notaría pública o en centro de reconciliación familiar o por decreto judicial.

La legislación de Colombia, en comparación con otros países de América Latina, quedó corta al no explicitar si las UMH tenían las mismas obligaciones recíprocas que los matrimonios sobre alimentos y sobre derechos sucesorios (Deere \& León, 2020). Estas responsabilidades fueron finamente reconocidas por la Corte Constitucional como equivalentes a las de las parejas casadas: en 2002, por sentencia C-1033 sobre los alimentos en el caso de separación, y en 2012, por la sentencia C-238 sobre la herencia.

11 Calculado por las autoras de CNPv 2018, Personas (Social), cuadro 7PD. https://www. dane.gov.co/index.php/estadisticas-por-tema/demografia-y-poblacion/censo-nacional-de-poblacion-y-vivenda-2018/herramientas.

12 Colombia seguido por Brasil fueron bastante excepcionales en América Latina en tomar en cuenta estas situaciones irregulares y muy comunes (Deere E León, 2020). Tal vez fue por el predominio de matrimonios católicos y el no reconocimiento del divorcio civil por la iglesia. 
Poner fin a la violencia contra la mujer ha sido una de las banderas de la segunda ola del movimiento feminista. ${ }^{13}$ Pero no fue sino hasta la aprobación en 1994 de la Convención Interamericana para Prevenir, Sancionar y Erradicar la Violencia contra la Mujer de Belém do Pará, que la mayoría de países de América Latina, incluido Colombia, promulgaron su primera legislación sobre violencia doméstica. ${ }^{14}$ La violencia $\mathrm{E} / \mathrm{P}$, como una forma de violencia en contra de la mujer, demoró casi dos décadas más en ser reconocida (Deere E León, 2020). ${ }^{15}$

Una vez ratificada la Convención Belém do Pará, ${ }^{16}$ Colombia aprobó la Ley 294 de 1996 sobre normas para prevenir, remediar y sancionar la violencia intrafamiliar, con énfasis en la violencia física, psicológica y sexual. En forma similar a otras leyes en América Latina, la norma se enfocó en la violencia intrafamiliar y no en la violencia de género contra las mujeres. Es decir, su meta principal fue proteger la familia y no el derecho de la mujer a una vida libre de violencia. El análisis de Sagot et al. (2000) para la región es relevante para el caso colombiano: "Esto no es producto de un descuido, sino de la resistencia de los sectores políticos nacionales a aceptar la existencia, gravedad y dinámicas propias de las formas de violencia que se ejercen contra las mujeres" (p. 20).

La Ley 294 de 1996 fue de gran importancia: creó la infraestructura para atender a víctimas de violencia doméstica como el procedimiento para plantear demandas ante las comisarias de familia o un juez civil, las medidas de protección inmediatas y definitivas a favor de la

13 El Primer Encuentro Feminista de América Latina y el Caribe, realizado en Bogotá, en 1981, propuso proclamar el 25 de noviembre como Día Internacional para la Eliminación de la Violencia contra la Mujer (Sagot, 2000), lo cual solo se logró en 2002.

14 Los antecedentes internacionales fueron la Convención de las Naciones Unidas sobre la Eliminación de todas las Formas de Discriminación contra la Mujer de 1979; la Conferencia Mundial sobre Derechos Humanos en Viena de 1993, y la Declaración de la Asamblea General de Naciones Unidas sobre la Eliminación de la Violencia contra la Mujer, también de 1993.

15 La excepción fue Costa Rica, que en 1996 definió la violencia patrimonial como la "Acción u omisión que implica daño, perdida, transformación, sustracción, destrucción, retención o distracción de objetos, instrumentos de trabajo, documentos personales, bienes, valores, derechos y recursos económicos destinados a satisfacer las necesidades" (artículo 2.3), definición modelo para otros países.

16 Ley 248 de 29 diciembre de 1995. 
víctima, y las multas por incumplimiento de las medidas. Aunque esta ley no mencionó la violencia E/P explícitamente, entre las medidas de protección definitivas reconoció la obligación del agresor a pagar por los daños ocasionados, es decir, por los costos de servicios médicos, psicológicos y psíquicos, o "la reparación o reposición de los muebles o inmuebles averiados" (artículo 5.c), ${ }^{17}$ aspectos que hacen referencia a la violencia $\mathrm{E} / \mathrm{P}$.

En la reforma del Código Penal, Ley 599 de 2000, se incluyó un nuevo capítulo para sancionar la violencia intrafamiliar física y psicológica. Otro capítulo se dedicó a una de las formas de violencia económica más comunes: el incumplimiento sin justa causa de la asistencia alimentaria a los familiares, entre ellos el cónyuge o compañero/a permanente, que fue delito penal desde 1968 con la Ley 75 de ese año.

A mediados de la década del 2000, era evidente que la ley contra la violencia intrafamiliar tenía graves deficiencias en su conceptualización e implementación. En la Defensoría del Pueblo se creó la Mesa de trabajo para la elaboración de una ley integral por el derecho de las mujeres a una vida libre de violencias, integrada por organizaciones de mujeres, académicas, entes gubernamentales y el sistema de Naciones Unidas. En el Congreso, por la misma época, se conformó la bancada de mujeres - senadoras y representantes-, que entre sus prioridades tenía el tema de la violencia contra la mujer. El intercambio entre la mesa de trabajo y la bancada de mujeres trajo como resultado la participación de la mesa en la subcomisión redactora del proyecto de Ley 171, el cual, después de varias modificaciones, fue aprobado como la Ley 1247 de 2008 (Ramírez Cardona, 2008).

La Ley 1247 dictó "normas de sensibilizar, prevenir y sancionar formas de violencia y discriminación contra la mujer", modificó y fue más amplia que la Ley sobre la violencia intrafamiliar de 1996, y reformó el Código Penal. Aunque no se logró todo lo deseado por la mesa de trabajo (Ramírez Cardona, 2008), esta ley reconoció, entre otros derechos, el de la mujer a una vida digna; a su integridad física, sexual

17 La Ley 294 fue parcialmente reformada por la Ley 575 de 2000 en la cual desapareció la frase sobre los daños ocasionados a los bienes. Este importante tema no se retomó hasta 2008. 
y psicológica; a la igualdad real y efectiva; a la no discriminación, y a la libertad y autonomía, e introdujo el concepto de violencia contra la mujer por ser mujer (artículos 6 y 27).

Un logro importante fue incluir explícitamente la violencia E/P como una forma de violencia contra las mujeres. La violencia económica se definió como "cualquier acción u omisión orientada al abuso económico, el control abusivo de las finanzas, recompensas o castigos monetarios a las mujeres por razón de su condición social, económica o política" (artículo 2). Además, reconoció que la violencia económica podría darse en múltiples niveles: en la relación de pareja, en las relaciones familiares, en lo laboral y en la economía (artículo 2). También desarrolló el concepto de daños contra la mujer y definió el "daño patrimonial" como la "pérdida, transformación, sustracción, destrucción, retención o distracción de objetos, instrumentos de trabajo, documentos personales, bienes, valores, derechos o económicos destinados a satisfacer las necesidades de la mujer" (artículo 3). Esta definición es casi igual a la de Costa Rica, país pionero en el tema, aunque se cambió el concepto de violencia por el de "daño".18

La ley amplió las medidas de protección e incluyó otras relevantes a la violencia patrimonial. Así, en el caso de una sociedad conyugal o patrimonial vigente, la autoridad judicial "puede prohibir al agresor la realización de cualquier acto de enajenación o gravamen de bienes de su propiedad sujetos a registro" y puede "ordenar al agresor la devolución inmediata de los objetos de uso personal, documentos de identidad y cualquier otro documento $\mathrm{u}$ objeto de propiedad o custodia de la víctima" (artículo 171 y m). Sobre la residencia, reiteró que la autoridad puede ordenar el desalojo del agresor y decidir provisionalmente el uso y disfrute de la vivienda familiar (artículo 17a y k). La autoridad también puede decidir provisionalmente quién tendrá a su cargo las pensiones alimentarias (artículo 17j).

La Ley 1247 del 2008 aumentó algunas de las sanciones previstas en el reformado Código Penal en el caso que el delito sea contra la mujer por ser mujer (artículo 27). Además, desarrolló las medidas de

18 Quedó un error de redacción en "derechos o económicos" que podría referirse a derechos y recursos económicos como dice la ley costarricense. 
sensibilidad y prevención de la violencia y las medidas de atención de responsabilidad del Estado a las víctimas. Finalmente, señala que la Consejería para la Igualdad de la Mujer coordinará, junto con la Procuraduría General de la Nación y la Defensoría del Pueblo, el seguimiento a la ley (artículo 35).

La Ley 1247 está reglamentada por decretos. ${ }^{19}$ A la vez se ha ampliado la legislación sobre la violencia de género contra la mujer en temas como la trata de personas, crímenes con ácido, violencia sexual en el conflicto armado y la tipificación y penalización del femicidio. ${ }^{20}$ Otros temas se han aclarado judicialmente, como la inclusión de parejas del mismo sexo en la legislación relevante a la violencia intrafamiliar. Entre las sentencias más importantes en relación con el reconocimiento de la violencia contra la mujer en sus múltiples dimensiones, la Sentencia T-017 de 23 de enero de 2017 de la Corte Constitucional reconoce que, por su magnitud en Colombia, esta "ha alcanzado un nivel estructural en nuestra sociedad, pues ha trascendido del plano individual hacia un plano político, social y económico".

\section{Violencia económica y patrimonial: dimensiones cuantitativas}

Las últimas encuestas especializadas en el tema ubican a Colombia entre los países de América Latina con incidencia más alta de violencia física contra las mujeres (Bott et al., 2012). Este dato puede estar relacionado con la larga historia de violencia política en el país, fenómeno que tiende a normalizar los diferentes tipos de violencia (FriedemannSánchez \& Grieve, 2019). Generalmente, se reconoce que la violencia social y la violencia doméstica están interrelacionadas de manera compleja (Buvinic et al., 1999), lo mismo que la violencia física, psicológica y E/P contra la mujer (Hasanbegovic, 2018).

19 Decreto 4.463 de 2011; Decreto 4.796 de 2011; Decreto 4.798 de 2011; Decreto 4.799 de 2011; Decreto 2.733 de 2012; y Decreto 2.734 de 2012.

20 Ver Ley 747 de 2012; Ley 1.639 de 2013; Ley 1.719 de 2014; y Ley 1.761 de 2015, respectivamente. 
México y Ecuador fueron los primeros países en incluir indicadores sobre la violencia E/P en sus encuestas sobre la violencia intrafamiliar, seguidos por Colombia en la Encuesta Nacional de Demografía y Salud (ENDS) de 2015 (Deere \& León, 2021). La tabla 1 presenta la incidencia de las diferentes formas de violencia de pareja contra la mujer en Colombia, a lo largo de la relación y por estado civil.

Tabla 1. Violencia de pareja contra la mujver alguna vez unida durante la relación, por forma y estado civil, 2015

\begin{tabular}{|c|c|c|c|c|c|c|}
\hline \multirow[b]{2}{*}{ Estado civil } & \multicolumn{5}{|c|}{ MUJERES (13 a 49 años de edad) } & \multirow{2}{*}{$\begin{array}{c}\text { No. de } \\
\text { mujeres } \\
\text { alguna vez } \\
\text { unidas }\end{array}$} \\
\hline & $\begin{array}{c}\text { Alguna } \\
\text { violencia } \\
\text { psicológica }\end{array}$ & $\begin{array}{c}\text { Alguna } \\
\text { violencia } \\
\text { física }\end{array}$ & $\begin{array}{c}\text { Alguna } \\
\text { violencia } \\
\text { económica }\end{array}$ & $\begin{array}{c}\text { Alguna } \\
\text { violencia } \\
\text { sexual }\end{array}$ & $\begin{array}{c}\text { Alguna } \\
\text { forma de } \\
\text { violencia }\end{array}$ & \\
\hline Casada & 54,5 & 22,9 & 23,0 & 4,7 & 57,4 & 6498 \\
\hline Unida & 61,8 & 27,4 & 25,4 & 4,9 & 64,4 & 12400 \\
\hline Viuda & 66,9 & 39,2 & 40,1 & 13,6 & 70,2 & 503 \\
\hline Divorciada & 84,5 & 58,0 & 64,6 & 22,9 & 87,1 & 245 \\
\hline Separada & 81,0 & 53,4 & 53,9 & 17,0 & 83,8 & 4873 \\
\hline Total & 64,1 & 31,9 & 31,1 & 7,6 & 66,7 & 24519 \\
\hline
\end{tabular}

Fuente: compilación de Profamilia de ENDS 2015.

Primero llama la atención que la incidencia de violencia E/P sea similar a la de violencia física, en el total. Casi un tercio de las mujeres en edad reproductiva reportan haber sufrido violencia $E / P$ alguna vez en su relación de pareja. La violencia psicológica es la más frecuente, seguida por la física, la E/P y la sexual. Segundo, es llamativo que las mujeres actualmente divorciadas o separadas reportan las tasas más altas de violencia. Este hecho puede tener dos explicaciones. La violencia de pareja puede ser razón principal o estar entre los motivos importantes que llevaron a la separación o divorcio. También sugiere que la violencia de pareja no termina con la disolución de la relación. La tabla 1 también muestra que, para las mujeres en UMH, la incidencia de alguna forma de violencia es más alta que para las casadas, tendencia que se mantiene en cada tipo de violencia, sea psicológica, física, E/P o sexual. 
La tabla 2 desglosa la violencia E/P contra las mujeres alguna vez unidas a lo largo de la relación por estado civil, y por las cinco preguntas que la midieron. En total, la violencia E/P más común llega a 16,2\%, cuando el hombre gasta el dinero destinado para el mantenimiento del hogar. En orden de importancia siguen: prohibirle trabajar o estudiar, vigilar el gasto del dinero, amenazar con quitarle el apoyo económico $y$, finalmente, adueñarse de su dinero o bienes.

Tabla 2. Violencia de pareja contra la mujer alguna vez unida durante la relación, por tipo de violencia económica/patrimonial y estado civil, 2015

\begin{tabular}{|l|c|c|c|c|c|c|}
\hline \multicolumn{1}{|c|}{ Tipo } & Casada & Unida & Viuda & Divorciada & Separada & Total \\
\hline $\begin{array}{l}\text { Se gastó dinero } \\
\text { necesario en la casa }\end{array}$ & 9,2 & 11,5 & 22,2 & 41,4 & 35,5 & 16,2 \\
\hline $\begin{array}{l}\text { Le ha prohibido } \\
\text { trabajar o estudiar }\end{array}$ & 9,3 & 11,9 & 23,8 & 28,1 & 24,1 & 14,0 \\
\hline $\begin{array}{l}\text { Le ha vigilado como } \\
\text { gasta el dinero }\end{array}$ & 10,8 & 11,1 & 14,8 & 31,0 & 22,4 & 13,5 \\
\hline $\begin{array}{l}\text { La ha amenazado con } \\
\text { quitarle apoyo económico }\end{array}$ & 5,9 & 6,8 & 12,8 & 35,9 & 24,7 & 10,5 \\
\hline $\begin{array}{l}\text { Se ha adueñado de dinero, } \\
\text { bienes o propiedades }\end{array}$ & 1,7 & 1,9 & 4,8 & 24,5 & 13,6 & 4,4 \\
\hline $\begin{array}{l}\text { Alguna violencia económica } \\
\text { o patrimonial }\end{array}$ & 23,0 & 25,4 & 40,1 & 64,6 & 53,9 & 31,1 \\
\hline $\mathrm{N}$ & 6498 & 12400 & 503 & 245 & 4873 & 24519 \\
\hline
\end{tabular}

Fuente: compilación de Profamilia de ENDs 2015.

La tabla 3 presenta la misma información para los últimos 12 meses. La incidencia de violencia $\mathrm{E} / \mathrm{P}$ es alta, pero no sorprende que sea menor, 23,4\%, comparada con el 31,1\% cuando se mide a lo largo de la relación. Por tipo de violencia, el más alto es también el gasto del dinero necesario para la casa, en particular entre las mujeres divorciadas y separadas, posiblemente por incumplimiento de la asistencia alimentaria para los hijos o esposa o compañera. Siguen en importancia las amenazas del exmarido o excompañero de retirar el apoyo económico. Este dato confirma que el control sobre las mujeres no termina con la disolución de la vida en común, aspecto observado en otros estudios (Hasanbegovic, 2018). 
Tabla 3. Violencia de pareja contra la mujer alguna vez unida durante los últimos 12 meses, por tipo de violencia económica/patrimonial y estado civil, 2015

\begin{tabular}{|l|c|c|c|c|c|c|}
\hline \multicolumn{1}{|c|}{ Tipo } & Casada & Unida & Viuda & Divorciada & Separada & Total \\
\hline $\begin{array}{l}\text { Se gastó dinero } \\
\text { necesario en la casa }\end{array}$ & 5,6 & 8,7 & 13,7 & 26,9 & 24,4 & 11,3 \\
\hline $\begin{array}{l}\text { Le ha prohibido } \\
\text { trabajar o estudiar }\end{array}$ & 4,4 & 8,9 & 11,3 & 19,2 & 14,8 & 9,0 \\
\hline $\begin{array}{l}\text { Le ha vigilado como } \\
\text { gasta el dinero }\end{array}$ & 8,7 & 9,9 & 10,7 & 19,6 & 15,7 & $10: 9$ \\
\hline $\begin{array}{l}\text { La ha amenazado con } \\
\text { quitarle apoyo económico }\end{array}$ & 4,1 & 5,9 & 8,0 & 24,5 & 17,1 & 7,9 \\
\hline $\begin{array}{l}\text { Se ha adueñado de dinero, } \\
\text { bienes o propiedades }\end{array}$ & 1,0 & 1,3 & 4,4 & 15,9 & 9,4 & 3,0 \\
\hline $\begin{array}{l}\text { Alguna violencia económica } \\
\text { o patrimonial }\end{array}$ & 15,7 & 21,2 & 25,0 & 39,6 & 38,3 & 23,4 \\
\hline N & 6498 & 12400 & 503 & 245 & 4873 & 24519 \\
\hline
\end{tabular}

Fuente: compilación de Profamilia de ENDS 2015

En los últimos 12 meses, las mujeres casadas y unidas muestran un patrón diferente. La vida en pareja lleva a que el tipo de violencia más común para ambos grupos de mujeres sea la vigilancia sobre el gasto del dinero, lo que significa limitar su autonomía. Para las casadas, y en forma similar para las unidas, les sigue en importancia el gasto del dinero de la casa y la prohibición de trabajar o estudiar. Se mantiene la tendencia señalada a lo largo de la relación, puesto que los diferentes tipos de violencia son significativamente más altos para las unidas que para las casadas. De las 503 viudas, el $25 \%$ reportaron presencia alta de cualquier tipo de violencia E/P de su pareja en los últimos 12 meses, lo que sugiere que la viudez puede ser reciente. A la vez, puede pensarse que sus respuestas mezclan lo que pasó cuando su pareja estaba viva y las consecuencias económicas de la viudez.

Las preguntas para medir la violencia E/P en el cuestionario de la ENDS muestran varias limitaciones. Solo una se refiere al patrimonio en cuanto el hombre se adueña de dinero y bienes. Fue la pregunta con más baja respuesta, solo un 4,4\% informó este tipo de violencia a 
lo largo de la relación (tabla 2), y solo el $3 \%$ en los últimos 12 meses (tabla 3), con alta variación según el estado civil.

A largo plazo, el 24,5\% de las divorciadas y el 13,6\% de las separadas reportó este tipo de violencia, y en los últimos 12 meses, el 15,9\% y $9.4 \%$, respectivamente. Lo anterior indica cómo este tipo de violencia se relaciona con el proceso de separación y divorcio. Es el momento en que los bienes están por dividirse, dando lugar a conductas de desaparición de bienes o uso de testaferros para poner los bienes a nombre de una tercera persona sin el conocimiento de la mujer (Deere et al., 2014).

Para un mejor entendimiento de la dinámica de la violencia E/P es necesario tener preguntas desagregadas. La encuesta de violencia de Ecuador (INEC 2019) pregunta por separado si "le ha quitado su dinero o lo ha gastado sin su consentimiento" y si "se ha adueñado de sus bienes o propiedades (casa, departamento, terrenos, vehículos, etc.)". Cada una de estas conductas es de diferente índole: la primera de violencia económica y la segunda de violencia patrimonial. Además, es importante desagregar aún más la pregunta sobre el dinero, para distinguir entre los ingresos propios de la mujer resultado de su trabajo y las transferencias que puede recibir de otros (como las remesas) o del Estado (como del programa Familias en Acción). De manera similar, sería útil desagregar la pregunta sobre la prohibición de estudiar o trabajar, pues la primera tiene implicaciones de largo plazo, y la segunda, de corto plazo.

Un paso aún más importante, pendiente en la recolección de información, es la diferencia entre la apropiación de bienes o propiedades que son parte del patrimonio individual de la mujer (adquiridos antes del matrimonio o por herencia o donación), y los bienes y propiedades adquiridos durante la relación, los cuales se deberían dividir por mitad al disolverse el matrimonio o unión.

La encuesta de Ecuador también incluyó otras preguntas sobre la violencia patrimonial que serían de gran interés para Colombia: si el hombre "le ha quitado o se ha apropiado de sus animales de crianza destinados para la venta o autoconsumo", pregunta importante para las mujeres rurales. También si "le ha quitado o destruido artículos personales, joyas u otros objetos de valor" y si "le ha quitado o destruido documentos personales o documentos que la acreditan como propietaria 
de un bien". Según la definición de violencia E/P de la Ley 1247, vale la pena preguntar sobre los instrumentos de trabajo de la mujer, ya sea relacionados con su trabajo doméstico (los bienes durables, como los de la cocina) o con sus actividades generadoras de ingresos.

Finalmente, es de resaltar que la encuesta de Colombia, con menos preguntas para medir la violencia E/P que la de Ecuador, arroga una incidencia de violencia más alta, tanto a lo largo de la relación como para los últimos 12 meses (Deere E León, 2020).

\section{La ruta crítica y la violencia económica y patrimonial}

La naturalización de la violencia de pareja en sus diferentes formas dificulta a las mujeres reconocerse como víctimas, conocer sus derechos y buscar apoyo para cambiar la situación. Este proceso de concientización y acción se conoce como la ruta crítica, y según la Organización Panamericana de Salud, "se construye a partir de la secuencia de decisiones tomadas y acciones ejecutadas por las mujeres afectadas por la violencia intrafamiliar y las respuestas encontradas en su búsqueda de soluciones" (Sagot et al., 2000, p. 90). La ruta crítica no se ha examinado en detalle para la violencia $\mathrm{E} / \mathrm{P}$.

Hay factores que impulsan el camino en la ruta crítica, entre ellos, que las mujeres tomen conciencia de su derecho a una vida libre de violencia, que la ley las proteja y que conozcan sus derechos de propiedad. Las encuestas de la Consejería Presidencial para la Equidad de la Mujer del 2009 y 2015, en diez ciudades del país, preguntaron si las mujeres conocen la legislación que protege a las víctimas de violencia y definen la violencia contra la mujer como un delito. En 2009, el $30 \%$ respondió afirmativamente, pero en 2015 , con otra muestra, solo un $18 \%$ lo hizo (Proyectamos 2015, p. 229-230). Esta información es preocupante dado que, entre una y otra medición, el Estado amplió sus esfuerzos de divulgación sobre los derechos de la mujer a una vida libre de violencia. Por otro lado, no sabemos de ninguna encuesta sobre el conocimiento de las mujeres acerca de sus derechos de propiedad. 


\section{La búsqueda de apoyo}

La información de la ruta crítica para Colombia es sobre violencia física, posiblemente por considerar la violencia de pareja más peligrosa y predecir el riesgo del femicidio. A continuación, se presentan los resultados de las ENDS del 2005, 2010 y 2015 sobre el tema.

Una característica de la violencia de pareja es que se da en la privacidad e intimidad del hogar. Por ello no es nada fácil compartir con otros lo que pasa; hay factores inhibidores como el miedo, la vergüenza, el amor por el agresor o la manipulación de este (Sagot et al. 2000). La ENDS 2015 preguntó por primera vez si las mujeres que han sufrido violencia física han buscado ayuda de personas cercanas. E1 43,6\% respondió positivamente, lo cual confirma que el primer paso en la búsqueda de apoyo es compartir la experiencia con alguien conocido: los padres $(50,3 \%)$, otro pariente $(35,6 \%)$ o amigos (25\%) (Profamilia 2015, cuadro 14.17).

Un paso más difícil es buscar apoyo institucional. Desde la primera encuesta, la ENDS preguntó si las mujeres violentadas buscaron ayuda institucional. Los resultados han oscilado: $23,9 \%$ en $2005,27,3 \%$ en 2010 y $23,6 \%$ en 2015 , lo cual muestra que no hay mejora en este indicador (Profamilia 2011, cuadro 13.12.1; 2015, cuadro 14.17).

En 2005 y 2010 también se preguntó a las mujeres que sufrieron violencia física por qué no buscaron apoyo institucional (Profamilia 2011, cuadro 13.13.1). En ambas encuestas, las razones fueron similares: la más común, pensar que el problema lo podían resolver solas, seguido de considerar que los daños no eran serios, o por temor a que si buscaban ayuda, aumentara la agresión.

La encuesta de 2015 detalló la experiencia de las mujeres que se acercaron a las instituciones. De las que buscaron apoyo, solamente el $20 \%$ denunció el hecho. Las mujeres de 45 a 49 años, de residencia urbana, con educación secundaria o superior, y del quintil medio a alto, fueron las más propicias a denunciar. El 39,8\% de las que denunciaron lo hicieron en una Comisaría de Familia, el 39,6\% en la Fiscalía y un 24,4\% en la Inspección de Policía (Profamilia, 2015, cuadro 14.18.1.1).

En el 22,1\% de los casos denunciados, el agresor fue sancionado con orden de no acercarse a ella, y en el 5,6\%, le prohibieron entrar a 
la casa de la mujer agredida, medidas temporales o permanentes que puede ordenar la Comisaría de Familia o la Fiscalía. Lo más común fueron otro tipo de sanciones $(30,0 \%)$ o la citación a conciliar con el agresor (29,5\%). El 28,2\% de las mujeres reportaron que el agresor no recibió ninguna sanción o que no se presentó a la conciliación, y el $7,1 \%$, que la violencia no paró, es decir, que la situación siguió igual o empeoró (Profamilia, 2015, cuadro 14.19.1.).

En suma, los datos muestran las dificultades que enfrentan las mujeres víctimas de violencia física para apoyarse en una institución y denunciar al agresor, y que el caso se resuelva de una manera favorable, lo que supone altas cuotas de impunidad.

\section{La respuesta institucional}

Los estudios disponibles sobre la respuesta institucional a la violencia contra la mujer generalmente concluyen que la prioridad es la atención a la violencia física. Relativamente poca atención se ha dado a la violencia $\mathrm{E} / \mathrm{P}$, con la excepción del incumplimiento de la asistencia alimentaria. Solamente un estudio, auspiciado por el Ministerio de Justicia y realizado en Buenaventura, Cartagena y Riohacha, ha profundizado sobre el tema de la violencia E/P (Sánchez Lara, 2017). Las entrevistas a los servidores públicos en las instituciones locales señalan una amplia gama de abusos y daños económicos y patrimoniales reportados por las mujeres que atienden. Aunque mencionan la violencia E/P, los funcionarios "en el momento de brindar atención no hacen una tipificación, sino que se reporta como violencia intrafamiliar o incumplimiento en cuota alimentaria, lo que impide tener datos relacionados con esta violencia en particular" (Sánchez Lara, 2017, p. 70).

Desde 2012, los lineamientos técnicos para las Comisarias de Familia señalan que en la recepción y registro de los casos de violencia contra la mujer se deben especificar todas las formas de violencia relevantes al caso, incluyendo la violencia E/P (Ministerio de Justicia, 2012, p. 56). Sin embargo, en el registro no se acoge esta directriz y los casos se reportan según el patrón tradicional, sin la violencia E/P. Por ejemplo, en el informe estadístico de la Comisaría de Familia de Buenaventura para 2013, donde se atendieron 344 casos, estos se desagregaron de la 
siguiente forma: $25,3 \%$ por violencia física, 12,9 por violencia psicológica, 10,1\% por violencia verbal, 44,8\% por inasistencia alimentaria y 2,3\% por abuso sexual o negligencia (Sánchez Lara, 2017, p. 29). No hay duda de que las demandas por alimentos predominan en la violencia económica, ya sea durante la convivencia o al terminar la relación. Según Jaramillo (2018, p. 137), estas demandas congestionan la justicia civil, con alrededor de un tercio de los casos, y la justicia penal, donde también son numerosos. Al reducir la violencia E/P al problema de inasistencia alimentaria se invisibilizan las demás manifestaciones de la violencia económica y se oculta la patrimonial.

La interrelación de las diferentes formas de violencia puede verse en los datos reportados por la Defensoría del Pueblo del Departamento de Bolívar para el año 2016 (tabla 4). Parece que el registro siguió los lineamientos técnicos al respecto. De 145 casos presentados, solo uno fue violencia patrimonial y ninguno fue solo de violencia económica, pero el 35,9\% de los casos incluyeron violencia económica o patrimonial. Por lo tanto, la interrelación de las diferentes formas de violencia resalta la importancia de la violencia E/P.

Tabla 4. Casos de violencia contra la mujer reportado por la

Defensoría del Pueblo, Departamento de Bolívar, 2016

\begin{tabular}{|l|c|c|}
\hline \multicolumn{1}{|c|}{ Forma de violencia } & Número de mujeres atendidas & $\%$ \\
\hline Física & 17 & 11,7 \\
\hline Psicológica & 11 & 7,6 \\
\hline Patrimonial & 13 & 0,7 \\
\hline Sexual & 5 & 9,0 \\
\hline Física, psicológica y patrimonial & 10 & 3,4 \\
\hline Física, psicológica y económica & 10 & 6,9 \\
\hline Física, psicológica, patrimonial y económica & 2 & 6,9 \\
\hline Física, psicológica, patrimonial y sexual & 3 & 1,4 \\
\hline $\begin{array}{l}\text { Física, psicológica, patrimonial, } \\
\text { sexual y económica }\end{array}$ & 8 & 2,1 \\
\hline Psicológica y patrimonial & 2 & 5,5 \\
\hline Psicológica y económica & & 1,4 \\
\hline
\end{tabular}




\begin{tabular}{|l|c|c|}
\hline \multicolumn{1}{|c|}{ Forma de violencia } & Número de mujeres atendidas & $\%$ \\
\hline Psicológica, patrimonial y económica & 5 & 3,4 \\
\hline Psicológico, física y patrimonial & 6 & 4,1 \\
\hline Física y psicológica & 44 & 30,3 \\
\hline Física, psicológica y sexual & 4 & 2,8 \\
\hline Psicológica y sexual & 4 & 2,8 \\
\hline Total & 145 & 100 \\
\hline
\end{tabular}

Nota: Datos parciales, enero a octubre de 2016.

Fuente: Sánchez Lara $(2017,33)$.

Según Sánchez Lara (2017), parte del problema del manejo de la violencia patrimonial es que la atención no se ha definido, lo que se relaciona con que las instituciones todavía no la ven como un delito. En entrevista con la Personería de Buenaventura,

la violencia económica y patrimonial siempre queda relegada frente a otros tipos de violencia y queda invisibilizada. Va una mujer a la Fiscalía y expone que el compañero le ha dañado sus bienes. Le recepcionan por agresión verbal o física y cuando se trata de los bienes le dicen que vaya y trate de conciliar o que busque un abogado y ponga una demanda civil para que le paguen los bienes (Sánchez Lara, 2017, p. 41).

Al parecer, en los procesos de conciliación que se realizan en las Comisarias de Familia, "no se hace mucho esfuerzo para que a la mujer le toque lo que le corresponde" (Sánchez Lara, 2017, p. 30). ${ }^{21}$

\section{La falta de conocimiento de los derechos de propiedad de la mujer}

El estudio de Friedemann-Sánchez (2012) sobre el conocimiento de las mujeres de sus derechos de propiedad, realizado con trabajadores

21 Otros estudios sobre las Comisarias de Familia también muestran la deficiencia que hay en la capacitación de los servidores públicos para atender la violencia contra la mujer en general, y particularmente, la violencia patrimonial. También han resaltado que las comisarías tienen demasiadas responsabilidades, y su presupuesto es insuficiente para dar atención adecuada (Ministerio de Justicia, 2012; Friedemann-Sánchez \& Grieve, 2019). 
rurales de bajos ingresos en el departamento de Cundinamarca, es el único que conocemos. En entrevistas a hombres y mujeres casados y en uniones libres, se encontró que la mayoría conocían que al casarse se formaba una sociedad conyugal, donde todo lo adquirido era propiedad de la pareja. Asimismo, había confusión sobre los derechos de propiedad de las parejas en unión. Todos los hombres en una unión libre y la mitad de las mujeres consideraban que lo adquirido durante la unión era propiedad de la persona que lo había comprado.

Esta misma autora sugiere que, en esta zona, donde la mayoría de hombres y mujeres son asalariados rurales, la práctica es que cada uno, sin importar su estado civil, controla su salario y considera que lo que compra es de su propiedad. También se confirmó que pocas de las parejas en uniones libres conocían que existen normas que regulan las UMH, y que, si la unión se registra, tienen los mismos derechos que los matrimonios en cuanto a propiedad compartida de lo adquirido durante la unión. ${ }^{22}$

Aunque desde 2005 las UMH se pueden reconocer en una notaría, relativamente pocas parejas las registran. La información disponible entre 2016 y 2018 indica que solamente 8597 parejas en promedio registran su unión anualmente. ${ }^{23}$ En el Censo de Población de 2018, 4,9 millones de mujeres declararon estar en unión libre. Si las mujeres registraran su unión con este promedio desde el 2005 (premisa improbable), el resultado sería que solamente un máximo de 2,5\% de las uniones estarían registradas.

Si la unión no está registrada, la única manera para que la mujer pueda hacer valer sus derechos de propiedad es pidiendo un juicio en el momento de separación o muerte de su compañero. Este trámite implica tener un abogado y probar que la unión satisface las condiciones necesarias para su reconocimiento como una UMH, es decir, probar con testigos que estuvo en una relación estable de convivencia de por lo menos 2 años. Un juicio es un proceso más costoso y complicado que el

22 Entrevistas por León en Pandi, 7 de agosto de 2019.

23 Compilado por las autoras de Superintendencia de Notariado y Registro, base de datos "Uniones maritales de hecho" en https://www.datos.gov.co 
registro ante un notario, que puede costar entre 162070 a 250000 COP, dependiendo del número de documentos y fotocopias involucradas. ${ }^{24}$

Uno de los factores asociados con la violencia patrimonial es la diferencia de género en los conocimientos de hombres y mujeres sobre la importancia de tener el título de propiedad de los bienes a su nombre. Según el estudio de Friedemann-Sánchez (2012), los hombres son más proclives que las mujeres a asegurarse de que lo que adquieran quede a su nombre. No importa si están casados o unidos, piensan que pueden hacer cualquier cosa con su propiedad, por ejemplo, vender o hipotecar un inmueble adquirido durante el matrimonio o unión. Friedemann-Sanchez (2012) considera que los notarios responsables de verificar los título de propiedad para su inscripción en el Registro de Propiedad, rara vez confirman el estado civil de la persona. ${ }^{25}$ Por lo tanto, un inmueble comprado con los recursos de ambos miembros de la pareja fácilmente se registra como de propiedad individual del hombre. Según su investigación, en la práctica, el título de propiedad tiene más peso que las normas sobre la sociedad conyugal en el código civil al momento de un divorcio o separación, lo que da como resultado violencia patrimonial contra la mujer. También se ha visto cómo los maridos ocultan o niegan a la mujer la parte correspondiente de los bienes adquiridos durante la unión (Sánchez Lara, 2017).

En la Sentencia T-012/16 de la Corte Constitucional, que ha tratado el tema de la violencia $\mathrm{E} / \mathrm{P}$ en más detalle, se reconoció cómo los efectos de esta clase de violencia

se manifiestan cuando existen rupturas de relación, pues es ahí cuando la mujer exige sus derechos económicos, pero, como sucedió a lo largo de la relación, es el hombre quien se beneficia en mayor medida con estas particiones. De alguna forma, la mujer "compra su libertad", evitando pleitos dispendiosos que en muchos eventos son inútiles (Corte Constitucional, 2016, p. 44).

24 Entrevistas telefónicas y comunicaciones por correo electrónico con notarias públicas en Bogotá y Pereira, abril y mayo de 2020. Las uniones de hecho también se pueden registrar con un Centro de Conciliación, donde la atención puede ser gratis o más económica.

25 Como en Colombia el estado civil no aparece en el carnet de identidad, esto hace aún más difícil, que en otros países, comprobarlo. 
La violencia patrimonial se agrava cuando la mujer no conoce sus derechos de propiedad y hay otras formas de violencia involucradas. Si la mujer no conoce sus derechos de propiedad y no contribuyó con ingresos al hogar, algunas veces piensa que todo lo comprado por el marido le corresponde a él. En situaciones de violencia física, la mujer hace cualquier cosa para salir de una relación insoportable o peligrosa y deja sus pertenencias personales - ni hablar de bienes muebles e inmuebles- (Sánchez Lara, 2017).

Es llamativo que en las ENDS 2015 y 2010 el 27,5\% de las mujeres respondieron que habían pensado separarse en algún momento durante los últimos 12 meses. El porcentaje donde la razón principal es la violencia de pareja subió de 29,9\% en 2010 a 45,7\% en 2015 (Profamilia 2015, cuadro 14.2.6.2; 2011, cuadro 13.9.1). Pensamos que entre las razones por las que no se separan o no denuncian la violencia está el temor a la desprotección, por no tener alternativas económicas. Este es el caso si las mujeres han sido amas de casa o solo han trabajado esporádicamente en el sector informal. Entre las preocupaciones también está que, si se separan, no tengan donde vivir con sus hijos, factor agravado cuando la pareja no ha tenido casa propia o si el título de la vivienda esta solamente a nombre del hombre. Sin casa o ingresos propios tienen poco poder de negociación para cambiar esa situación de violencia.

\section{Conclusión}

Este trabajo muestra la larga y dura lucha para derogar legalmente los elementos de la potestad marital, proceso que culminó con el reconocimiento de la violencia E/P como una forma de violencia contra la mujer. Se evidencian dos procesos: avances jurídicos y continuidades culturales. La lógica patriarcal colonial que hereda y proyecta la normatividad republicana se va modificando, lo que significa que se van dando condiciones necesarias para cambios culturales. Sin embargo, estos no han sido suficientes. El resultado se aprecia en la prevalencia de la lógica patriarcal, por lo que estamos lejos de eliminar todas las manifestaciones de la violencia en la vida de las mujeres. 
Es prioritario promover el alfabetismo legal para que las mujeres conozcan sus derechos de propiedad y su derecho a una vida libre de violencia. Sobre los derechos de propiedad, es de especial importancia divulgar los beneficios que el registro de la UMH puede tener para las mujeres en unión libre porque en la actualidad son la mayoría de las que viven en pareja. Además, el alfabetismo legal es la palanca para que las mujeres que han sufrido violencia emprendan la ruta crítica de concientización y acción para cambiar o salir de su situación.

Aunque se registran avances en la atención estatal a la violencia contra la mujer, especialmente después de la Ley 1247 de 2008, la atención es aún deficiente, en particular para la violencia E/P. El desconocimiento de los funcionarios estatales llega al punto de no considerar la violencia E/P como delito. Además, la atención institucional no se ha definido claramente, aspecto que trae como resultado un alto grado de impunidad. Es necesario fortalecer las instituciones. Urge que el movimiento de mujeres, que impulsó esta ley, redoble sus esfuerzos para lograr su efectivo cumplimiento en alianza con la cooperación internacional.

Queremos enfatizar la situación alarmante de las mujeres separadas y divorciadas, quienes reportan la incidencia más alta de todas las formas de violencia, incluyendo la violencia E/P. Esta información refuerza nuestro argumento sobre la interrelación entre las diferentes formas de violencia. Es muy importante resaltar el rol de la violencia en las rupturas y también que la violencia no termina al disolverse la relación de pareja, lo que crea una verdadera encrucijada para las mujeres.

Dada la dependencia económica, es muy difícil para las mujeres salir de una relación violenta. A la vez, para la mujer con hijos, la separación o divorcio reproduce la dependencia económica por la necesidad de asistencia alimentaria del agresor y es sobre ella que recae el cumplimiento de esta asistencia. Este proceso puede generar aún más violencia de parte de la expareja. Aun cuando se cumple con los alimentos, una madre desempleada o con pocas alternativas en el mercado laboral, rara vez logra salir de la pobreza.

La investigación apunta a la importancia de fortalecer la posición de resguardo de la mujer. Son necesarios programas enfocados en el empleo, la adquisición de activos o ambos. Aunque se reconoce que tener 
un ingreso y bienes propios no elimina la violencia de pareja, sí amplía el poder de negociación de las mujeres y sus alternativas frente a esta.

\section{Referencias}

Alviar García, H. (2018). Violencia económica contra la mujer y deber de alimentos en Colombia: visiones teóricas en conflicto. Comparative Law Review, 9(1), 4-28.

Amézquita de Almeida, J., León de Leal, M., \& Motta de Correa, L. (1977). Condiciones de la mujer en el derecho de familia. En M. León de Leal (Coord.), La mujer y el desarrollo en Colombia (pp. 273-315). ACEP.

Beltrán, \& Puga Murai, A. L. (2019). Movilización feminista y derecho de familia: la regulación del divorcio civil en Colombia. (Tesis doctoral, Universidad de los Andes, Bogotá, Colombia).

Bott, S., Guedes, A., Goodwin, M., \& Adams Mendoza, J. (2012). Violence against women in Latin America and the Caribbean. A comparative analysis of population-based data from twelve countries. PAHO and Centers for Disease Control and Prevention.

Buvinic, M., Morrison, A., E Shifter, M. (1999). Violence in Latin America and the Caribbean: A framework for action. Inter-American Development Bank.

Colombia, Congreso de la República. Código Civil Colombiano expedido por el Congreso de 1873, Adoptado por la Ley 57 de 1887. https://www.funcionpublica.gov.co/eva/gestornormativo/norma.php?i=39535

Corte Constitucional. (2016). Sentencia T-012/16, "Discriminación y violencia contra la mujer" de 22 de enero de 2016. Magistrado Ponente, Luis Ernesto Vargas Silva.

Costa Rica, Asamblea Legislativa. Ley 7586, Ley contra la violencia doméstica de 2 de abril de 1996. www.oas.org/dil/esp/Ley_contra_violencia_domestica_costa_rica.pdf

Deere, C. D. (2020). Marital regimes and women's economic autonomy: South American reforms of the early twentieth century. (Trabajo no publicado). Universidad de Florida.

Deere, C. D., G León, M. (2002). Género, propiedad y empoderamiento. tierra, Estado y mercado en América Latina. UNAm y Flacso-Ecuador.

Deere, C. D., G León, M. (2005). El Liberalismo y los derechos de propiedad de las mujeres casadas en el Siglo XIX en América Latina. En M. León \& 
E. Rodríguez, ¿Ruptura de la inequidad? Propiedad y género en la América Latina del siglo XIX (pp. 29-103). Siglo del Hombre.

Deere, C. D., E León, M. (2020). Consensual unions, property rights and patrimonial violence against women in Latin America. (Trabajo no publicado). Universidad de Florida y Universidad Nacional de Colombia.

Deere, C. D., Twyman, J., E Contreras, J. (2014). Género, estado civil y la acumulación de activos en el Ecuador: una mirada a la violencia patrimonial. Eutopía, (5), 93-119.

Esteve, A., Saavedra, A. C., López-Colás, J., López-Gay, A., E Lesthaeghe, R. J. (2016). The boom of cohabitation in Colombia and in the Andean Region: Social and spatial patterns. En A. Esteve E R. J. Leshaeghe (Eds.), Cohabitation and marriage in the Americas: Geo-historical legacies and new trends (pp. 187-215). Springer.

Friedemann-Sánchez, G. (2012). Legal literacy and immovable property: Laws, norms and practices in Colombia. Development and Change, 43(6), 1361-1384.

Friedemann-Sánchez, G., E Grieve, M. (2019). Comisarías de familia y violencia contra las mujeres en Colombia: puerta de acceso y retos institucionales. Taller de Edición Rocca.

Glendon, M. A. (1989). The transformation of family law: State, law and the family in the United States and Western Europe. The University of Chicago Press.

Gómez Chíquiza, M. E. (2019). Aspectos patrimoniales en las relaciones de familia consagradas en el Código de Andrés Bello y su vigencia en la sociedad contemporánea. En F. Navia Arroyo \& C. A. Chinchilla Imbett (Eds.), La vigencia del Código Civil de Andrés Bello. Análisis y prospectivas en la sociedad contemporánea (pp. 168-199). Universidad Externado.

Gómez Molina, P. M. (2015). Régimen patrimonial del matrimonio: contexto histórico que rodeo la promulgación de la Ley 28 de 1932. Revista de Estudios Socio-Jurídicos, 17(1), 41-76.

Hasanbegovic, C. (2018). Ataques a la libertad. Violencia de género económicopatrimonial contra las mujeres. Revista Jurídica de Buenos Aires, 97, 167-98. INEC-Instituto Nacional de Encuestas y Censos. (2019). Encuesta nacional sobre relaciones familiares y de violencia de género contra las mujeres (Envigmu). http://www.ecuadorencifras.gob.ec/violencia-de-genero

Jaramillo Sierra, I. C. (2013). Derecho y familia en Colombia. Historias de raza, género y propiedad (1540-1980). Universidad de los Andes.

Jaramillo Sierra, I. C. (2018). El papel del derecho en la producción de la desigualdad: El caso de los alimentos. Comparative Law Review, 9(1), 120-142. 
Luna, L. G. (1985). Los movimientos de mujeres: feminismo y feminidades en Colombia (1930-1943). Boletín Americanista, 35, 169-190.

Ministerio de Justicia y del Derecho. (2012). Justicia y Género. II Lineamientos técnicos en violencias basadas en género para las comisarías de familia. Imprenta Nacional de Colombia.

Mirow, M.C. (2001). Borrowing private law in Latin America: Andres Bello's use of the code Napoleon in drafting the Chilean civil code. Lousiana Law Review, 61 291-329.

Profamilia. (2011). Encuesta nacional de demografia y salud 2010. Profamilia y Ministerio de la Protección Social.

Profamilia. (2015). Encuesta nacional de demografía y salud 2015. Tomo II. Profamilia y Ministerio de Salud.

Proyectamos, Colombia S.A. (2015). Segunda medición del estudio sobre tolerancia social e institucional de las violencias contras las mujeres. Consejería Presidencial para la Equidad de la Mujer.

Ramírez Cardona, C. C. (2008). Aprobación de la Ley sobre Violencia contra la Mujer. Experiencia de la Mesa por la ley. (Trabajo inédito).

Sagot, M., Carcedo, A., E Guido, L. (2000). La ruta crítica de las mujeres afectadas por la violencia intrafamiliar en América Latina. Organización Panamericana de Salud.

Sánchez Lara, M. (2017). Violencia económica y patrimonial: Una aproximación a través de la atención en los municipios de Riohacha, Buenaventura y el Distrito de Cartagena. (Documento sin publicar). AECID y Ministerio de Justicia y del Derecho.

Valencia Zea, A. (1987). Derecho Civil, Tomo I, Parte General y Personas. Temis. Valencia Zea, A., E Ortiz Monsalve, A. (1995). Derecho civil. Derecho de familia. Tomo $v$. Temis.

Velásquez Toro, M. (1989). Condición jurídica y social de la mujer. En A. Tirado Mejía (Dir.), Nueva historia de Colombia, Tomo IV (pp. 9-60). Planeta. 